\title{
Approach to Lithuanian energy supply state assessment
}

\author{
J. Augutis ${ }^{1,2}$, E. Ušpuras ${ }^{1} \&$ V. Matuziene ${ }^{1}$ \\ ${ }^{1}$ Lithuanian Energy Institute, Lithuania \\ ${ }^{2}$ Vytautas Magnus University, Lithuania
}

\begin{abstract}
Energy supply in Lithuania will be particularly vulnerable after the Ignalina Nuclear Power Plant (NPP) shutdown at the end of 2009, when a new power plant is designed. Presently, gas supply is expensive and unreliable, and electricity connections with western countries have not been built. Technical, economical, social political and terrorist disturbances will become very important, as well as the ability of the Lithuanian energy sector to overcome these obstacles and the consequences which are important to foresee for decision makers. In this paper a methodology is presented to assess an energy security level, the assumptions taken into account, data collected for the model, and prior economical analysis results are shown. The model is in the building stage. It will be created for the assessment of the risks using probabilistic safety analysis on the SES RISK framework. The real composition of Lithuanian energy supply (energy sources, networks) is reflected in the model, possible initiating events are taken into account, and their probabilities are determined by expert methods or modelled using an economical model.
\end{abstract}

Keywords: Lithuanian energy supply, energy supply assessment.

\section{Introduction}

Lithuanian energy supply is a special case from a security point of view. The Lithuanian nuclear sector is one of the most sensitive sectors from the viewpoint of security of the power supply due to its magnitude and economy of scale of NPPs, as well as due to dependence on government policy. Besides, the acceptance of public and proper probabilistic assessment of experts is an important condition in order to ensure the operation of NPPs. 


\section{General methodology of the modelling}

After state of the art analysis and trying different methods for energy security assessment, there were cristalised main parts of modelling (see Figure 1) analysis of energy disturbances and threats, evaluation of energy security by security indicators, where economical modelling could take place for security indicators evaluation, modelling of the possible energy system disturbance scenarios and evaluation of general security level after consequences analysis and these parts are connected somehow with other analysis (sensitivity, uncertainty, etc.). Some of the parts were presented in conference papers: security indicators system for nuclear energy [3], economical modelling results of scenarios [4], mathematical modelling of disturbance scenarios [5]. In this paper we would like to present modelling of possible disturbance scenarios using the techniques as fault trees and event trees building with RiskSpectrum.

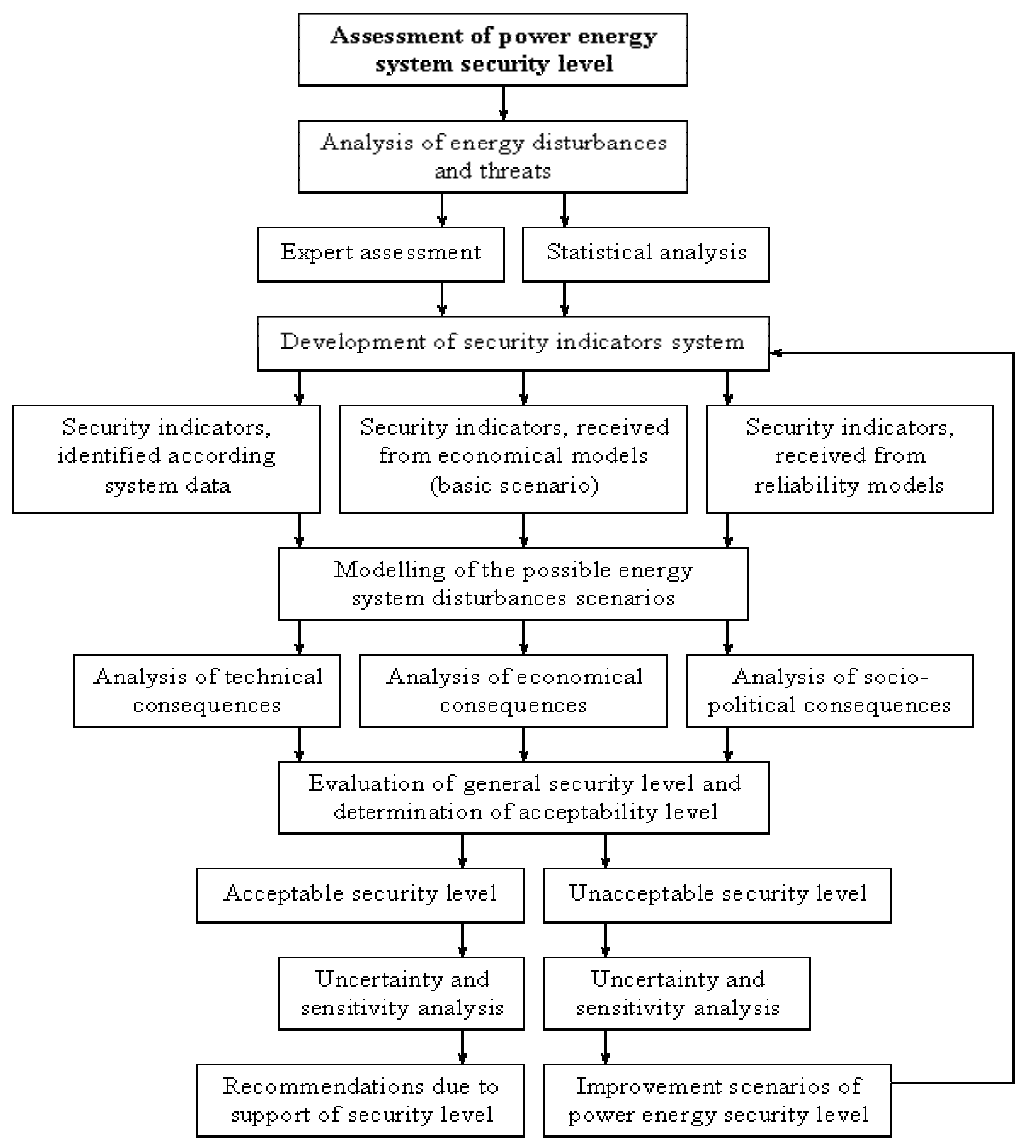

Figure 1: General scheme of methodology. 


\section{Model}

In the model, the Lithuanian energy system is composed of energy sources (nuclear, gas, oil products, renewable energy, etc.) and input (e.g. primary energy supply network) and output grids (the electricity and heating networks).

It is shown how subsystems of the Lithuanian energy sector are able to cope with technical, economical, terrorist and socio-political challenges in the model. Dependencies among subsystems (plants using certain kind of energy sources and energy transmission grids) are explicitly taken into account. The model is incorporating a lot of quantitative and qualitative expert view data.

The results can be presented in the form of suggested actions based on the identified weaknesses of the network.

The Lithuanian energy supply evaluation model is based on SES RISK [1]. Essentially, SES-RISK describes how well the energy supply network reacts to challenges when it faces them [1,6]. SES-RISK uses probabilistic risk assessment (PRA) and can assess vulnerabilities of complex systems. It uses event and fault trees to evaluate the resilience of a system to a particular challenge.

Initiating events or challenges, barriers come in four types: technical, economic, socio-political and terrorist. Each of these threat types has one of three associated degrees of severity (1-low, 2-medium, and 3-high).

Initial conditions of the energy system may add to the challenge. The degree of resilience of a particular part of the energy supply system is expressed in one of four levels: normal initial state, low, medium or high disturbance. These initial conditions are derived via a first PRA by developing event and fault trees considering scenarios.

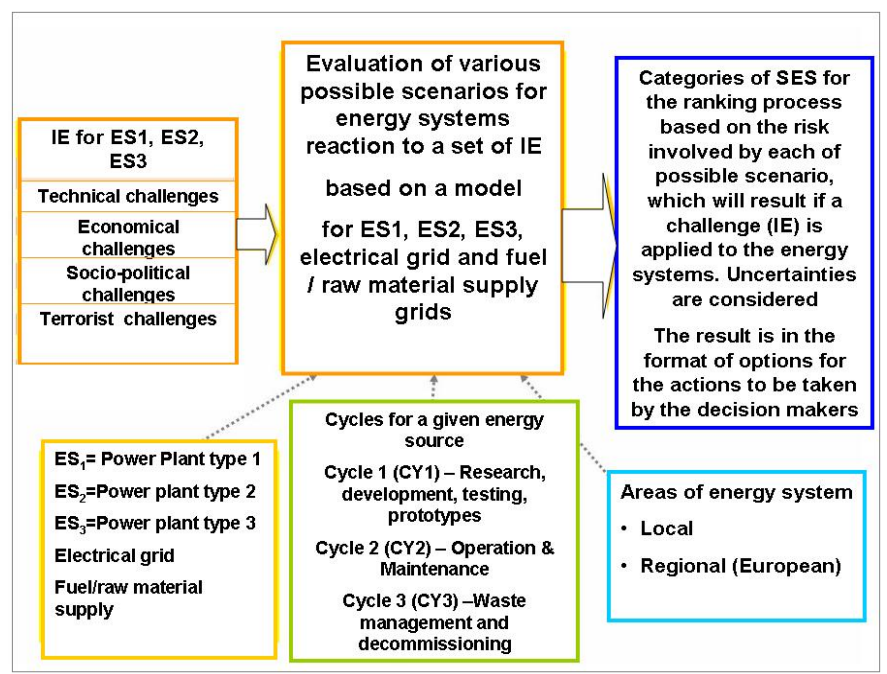

Figure 2: $\quad$ General SES-RISK model [1]. 


\section{General SES RISK sample RESULTS}

All the results can be classified into three survivability's levels [1]. Later they are grouped by two criterions: rank of impact and confidence in results to four groups as shown in Table 1.

Table 1: Example of the risk ranking for all final states: high survivability level 3 [1].

\begin{tabular}{|l|l|l|l|}
\hline $\begin{array}{l}\text { Components and their occurrence / } \\
\text { failure impact for a SES state of type } \\
\text { SURV3 }\end{array}$ & $\begin{array}{l}\text { Rank of } \\
\text { Impact }\end{array}$ & $\begin{array}{l}\text { Confidence } \\
\text { in results }\end{array}$ & $\begin{array}{l}\text { Group of } \\
\text { impact }\end{array}$ \\
\hline $\begin{array}{l}\text { Failure of the barrier defined by System 2 } \\
\text { of TR type, for ES2 in cycle CY1 }\end{array}$ & $\mathrm{H}$ & $\mathrm{L}$ & $\mathrm{I}=\mathrm{HL}$ \\
\hline $\begin{array}{l}\text { Failure of the barrier defined by System 2 } \\
\text { of E type, for ES1 in cycle CY3 }\end{array}$ & $\mathrm{H}$ & $\mathrm{M}$ & $\mathrm{II}=\mathrm{HM}$ \\
\hline $\begin{array}{l}\text { Occurrence of an IE (Challenge) to OGR } \\
\text { of T2 type in cycle CY2 }\end{array}$ & $\mathrm{M}$ & $\mathrm{L}$ & $\mathrm{III}=\mathrm{ML}$ \\
\hline Initial condition of worst type (GC3) & $\mathrm{H}$ & $\mathrm{H}$ & $\mathrm{IV}=\mathrm{HH}$ \\
\hline
\end{tabular}

Minimal cut sets of the scenario show the general conditions state, initiating event and failed functional safety barriers - all the situation that led to the particular survivability level. For example, challenge consists in a technical failure of barrier 2 of ES1 (e.g. failure of safety systems discovered during the operation of the nuclear power plant, i.e. CY2) leading to the preventive shut down of the plant. This then results in the disruption of electricity supply to the grid, even if there is no impact on the environment, workers and public.

The decision-maker could consider, as a priority, just to improve the safety systems. However, this may not be the best course of action from the perspective of assuring survivability of category 3 of the entire energy system, as this scenario has a high-risk impact but low confidence (see Table 1). Thus, based on his/her boundary conditions, the decision-maker may decide to choose another scenario.

\section{Assumptions of model}

After the energy system has been defined, a number of assumptions have to be made:

I. How to determine time in the model?

II. How are energy types and grids connected?

III. How barriers are dependant on each other? For example a major failure of the electricity barriers (switchers, control systems, and dispatcher) is likely to have economic effects, thus weakening the robustness of the economic barrier?

IV. What are the initial conditions of the system (see above)? 
V. What impact to the system has different consequences? How should results be grouped in order of importance and relevance to a decision?

\subsection{Time frame in the model}

In the model three time scenarios were researched:

a. Scenario 1 - 2008-2010 years: main electricity generating source Ignalina Nuclear Power Plant is in operation.

b. Scenario 2 - 2010-2018 years: no operating nuclear power plant in Lithuania. It means that the main electricity generating source, which generated $60-89 \%$ of all generated electric energy, is closed.

c. Scenario 3 - 2018-2025 years: new nuclear power plant reactors (500$1500 \mathrm{MW}$ or even bigger capacity reactors) are planned to be built.

\subsection{Modelled types of energy sources for generating energy and grids: connections among them}

The modelled energy sources and grids are shown in Table 2.

Table 2: $\quad$ Primary energy sources and grids of Lithuania used in model.

\begin{tabular}{|l|l|}
\hline Code & Primary energy source or grid \\
\hline ES1 & Nuclear energy (Ignalina Nuclear Power Plant) \\
\hline ES2 & $\begin{array}{l}\text { Planned Nuclear energy (Planned to build Visaginas Nuclear Power } \\
\text { Plant) }\end{array}$ \\
\hline ES3 & $\begin{array}{l}\text { Natural gas (Lithuanian PP, Vilnius CHP, Kaunas CHP, Mazeikiai } \\
\text { CHP, Jonava Achema CHP, Klaipeda CHP, Heat Plants, Other Plants) }\end{array}$ \\
\hline ES4 & $\begin{array}{l}\text { Oil \& products (Lithuanian PP, Vilnius CHP, Kaunas CHP, Mazeikiai } \\
\text { CHP, Jonava Achema CHP, Klaipeda CHP, Heat Plants, Other Plants) }\end{array}$ \\
\hline ES5 & $\begin{array}{l}\text { Renewable PP existing (Wind PP, Kruonis HPS, Kaunas HPP, Small } \\
\text { HPP) }\end{array}$ \\
\hline ES6 & Renewable PP planning \\
\hline IGG & Input grid gas (Country-supplier of primary natural gas - Russia) \\
\hline IGO & $\begin{array}{l}\text { Input grid oil (Primary natural crude oil source supplier - Russia. It is } \\
\text { supplied via Butinge terminal after stopping to supply via Druzba on } \\
\text { July 2006) }\end{array}$ \\
\hline OG1 & $\begin{array}{l}\text { Output grid electricity internal - internal supplying electricity to } \\
\text { consumers }\end{array}$ \\
\hline OG2 & $\begin{array}{l}\text { Output grid electricity external: Russia, Latvia, Belarussia - existing } \\
\text { network to East countries }\end{array}$ \\
\hline OG3 & $\begin{array}{l}\text { Output grid electricity external: Sweden, Poland, UCTE - network to } \\
\text { West countries }\end{array}$ \\
\hline OGH & Output grid heat - internal supplying heat to consumers \\
\hline
\end{tabular}

An example of connection matrix among energy sources and grids in scenario 1 are shown in Table 3. 
Table 3: Matrix of connection among energy sources and grids in time scenario 1 .

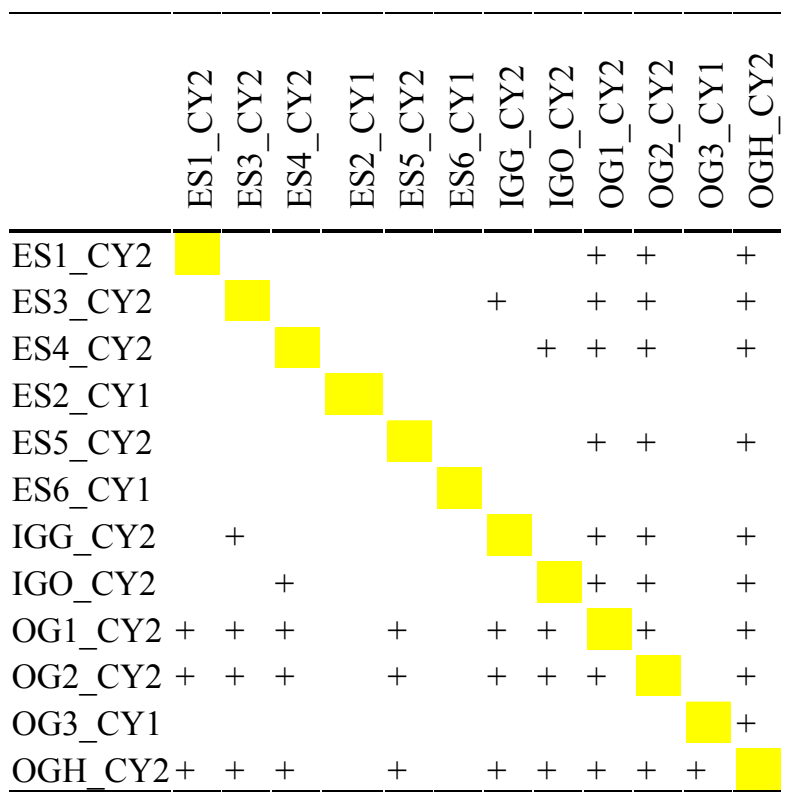

The situation of Lithuanian safety and security of electric energy supply is unique and quite complicated in comparison to other European countries: few countries supply primary energy sources, there are no networks of gas, oil and electricity to Western Europe and the power transmission grid needs modernization.

Nuclear is still the main source of electric energy in Lithuania: it covers $60-86 \%$ of total electricity production. Nuclear fuel to Lithuania is imported only from Russia, taking into account the fact that reactors operating in the Ignalina Nuclear NPP are RBMK (reactor of high power of the channel type), for which fuel is produced only in Russia.

\subsection{Barriers dependability on each other}

The barriers are dependable on each other, e.g., a major failure of the electricity barriers (switchers, control systems, and dispatcher) is likely to have economic effects, thus weakening the robustness of the economic barrier.

The interconnections between the barriers of the energy system illustrated in Figure 3 are chosen by the modeller in a binary matrix format where " 1 ", (logic true) means that barrier elements are dependant) and " 0 ", indicates independence (Table 4). 


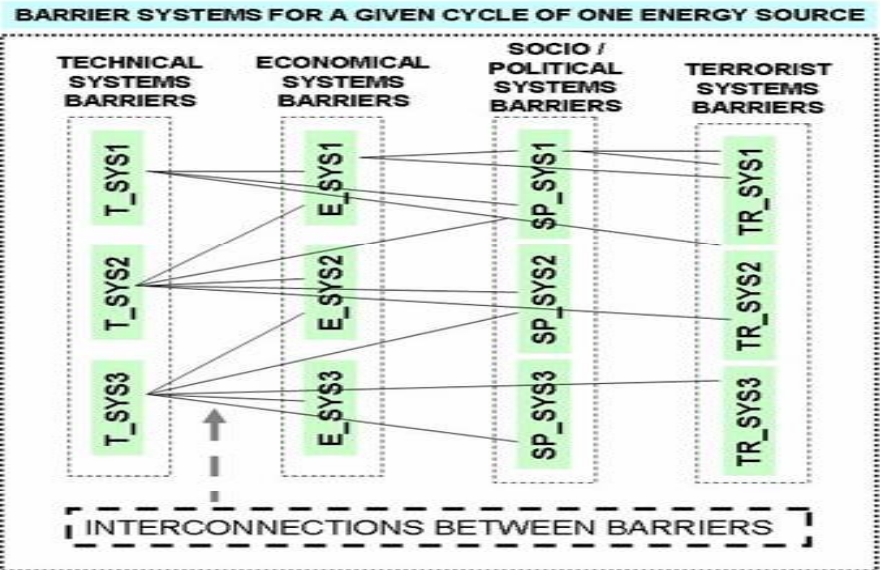

Figure 3: Representations of the components of SES pilot case [1].

Table 4: Interconnection between barriers.

\begin{tabular}{|l|l|l|l|l|l|l|}
\hline & T1 & T2 & E1 & E2 & SP1 & SP2 \\
\hline T1 & 1 & 0 & 1 & 0 & 0 & 0 \\
\hline T2 & 0 & 1 & 1 & 1 & 1 & 1 \\
\hline E1 & 1 & 1 & 1 & 0 & 0 & 1 \\
\hline E2 & 0 & 1 & 0 & 1 & 1 & 1 \\
\hline SP1 & 0 & 1 & 0 & 1 & 1 & 0 \\
\hline SP2 & 0 & 1 & 1 & 1 & 0 & 0 \\
\hline
\end{tabular}

\subsubsection{The initial conditions of the system}

Initial conditions of the system can be described by general conditions. It is possible to build different event trees to every energy source and different fields.

\section{Pipelines}

Lithuanian electricity network, gas and oil pipelines were built on Soviet times. The recent electricity network and pipelines are old. Investments to their renovation are very small. Construction of oil pipelines in Lithuania started in 1966, with the first crude oil being put through them in 1968. After closing the Druzba pipeline in July 2006 oil is transported only by ships to Butinge terminal.

\section{Energy produced}

Import of electricity contains $10 \%$ of all electricity demand in Gross Production in Lithuania in 2007 [7].

\section{Supply/Demand}

Lithuania have oil reserves for 63 days. Lithuania doesn't have LNG terminal. The types of initiating events for the energy sources are classified as shown in Table 5. 
Table 5: $\quad$ Initiating events.

\begin{tabular}{|l|l|}
\hline Notation & \multicolumn{1}{|c|}{ Type of initiating event } \\
\hline T1 & Internal breakdown \\
\hline T2 & Release of particles/substances/radiation to atmosphere \\
\hline E1 & Lithuanian market disruption \\
\hline E2 & European Market disruption \\
\hline SP1 & Public movement inside Lithuania \\
\hline SP2 & Movement in European level \\
\hline TR1 & National terrorism \\
\hline TR2 & International terrorism \\
\hline
\end{tabular}

Describing technical initiating events in NPP we use classification: T1 Large breaks in Power Plants (LOCA, ...), T2 - Release to atmosphere. Describing technical events in grids we use: T1 - Breakdown without stopping supply, T2 - Breakdown with stopping supply.

Data for technical, terroristic challenges, functional events were selected from studies of expertial assessment and probabilistic modelling. Reports of probabilistic assessment of Ignalina Power Plant, Kaunas and Kruonis Hydropower plants, electricity network, heat network are made by Lithuanian energy institute. We used scientific research studies [8-11].

Data for economical, socio-political challenges, functional events were selected from different sources. The logarithmic scale method was used (Center of Strategic studies in Lithuania, Centre for European Policy studies): hypothetical classification of risks to low (0.1-1\% of all possible cases), medium (1-10\%), high (10-100\%). In Vytautas Magnus University, it is initiated project where sociological questionnaires on energy security issues are developed. The functional interdependencies method (V. Bykova, Moldavian scientist) could help to find critical threshold value of secure indicators. The method is based on indicators system with main indicator (GDP, energy system costs) and interdependencies of secure indicators.

Economical modelling using MESSAGE software was performed by Norvaisa E., Galinis A. in the Lithuanian Energy Institute. The modelling gives proper functional events: energy supply options in different scenarios and consequences (such as unsupplied energy and price rising). E.g. challenge - oil product (heavy fuel oil) disruption; model shows barriers in different periods and different quantities of disruption: Safety barrier 1 - using necessary energy from storage; Safety barrier 2 - buying necessary energy for higher price; Safety barrier 3 - changing the necessary energy source by another energy source (e.g. gas). The consequences here could be higher electricity and heating price. The worse consequence could be unsupplied energy for consumers.

Fuel consumption on normal operation (when the challenges are level 0 ) is shown in Figure 4.

The fuel consumption option on economical, socio-political challenge for ES3 (Gas disruption) in 2017 (MESSAGE) is shown in Figure 5. 


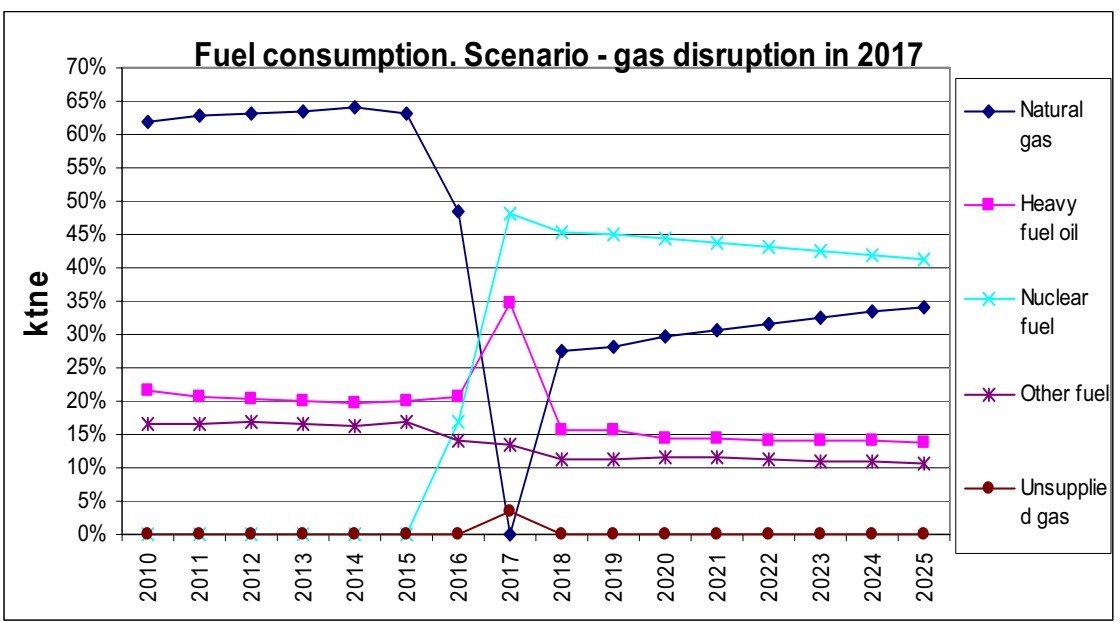

Figure 4: Fuel consumption. Basic scenario. Challenges are level 0.

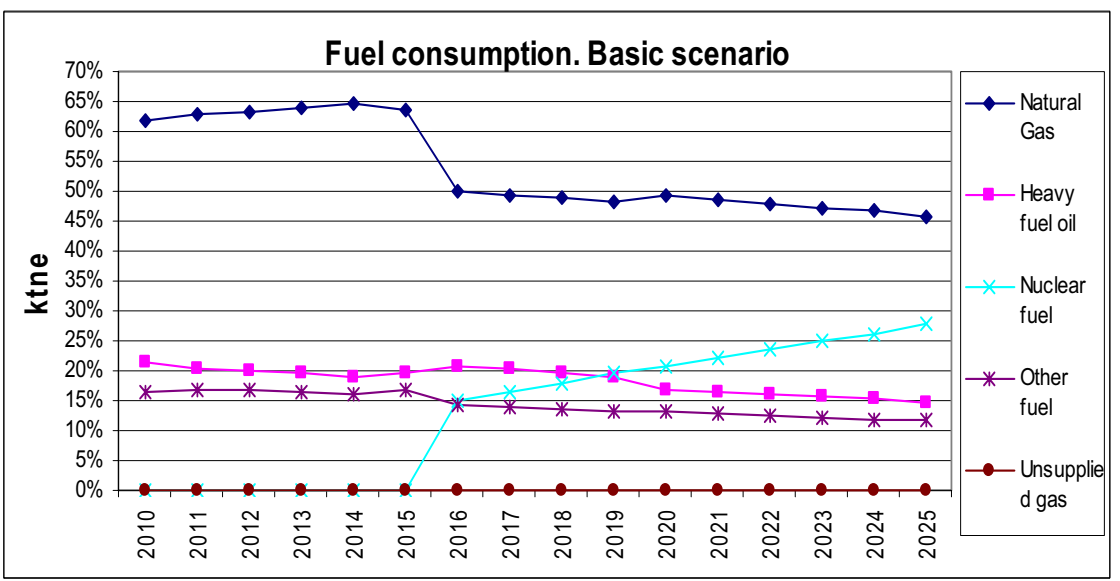

Figure 5: Fuel consumption. Challenge level 3 (total disruption) to natural gas supply on 2017.

As can be seen in the figures, the economical modelling of Lithuanian energy system gives not only costs of energy system, but also unsupplied energy quantity and what options of energy sources are used.

The useful lessons learned on economical modelling of one challenge disruption scenarios were:

- Low level disturbances of electric energy (reducing to 50\% from basic scenarios) of different fuel types (gas, oil, heavy fuel oil, nuclear fuel) does not substantial harm the Lithuanian energy system. 
- When gas supply decreases to $95 \%$ for a year, gas supply is stopped to Lithuanian enterprises but electricity and heat is then produced by heavy fuel oil. Therefore, costs of energy production rise by $\$ 51$ million per year on average.

- A critical situation is reached when the supply of two fuel types to Lithuania is stopped.

\subsection{Consequences of disruption: survivability categories}

Consequences of the different disturbances are of a different level, e.g. the different challenges - break of steam separator in NPP and absence of wind in the area of wind mils - have very different meanings for the energy system. The importance of the consequences has to be shown. The weight of consequences can simply be determined according to generated/forecasted to generate energy quantity.

There were left the same concepts in model as SES RISK for the grouping and ranking the scenarios [1] mentioned in section 4. At PRA level 3, the end states of level 2 (the combination of scenarios leading to a specific survivability level) are ranked by two criteria: one is the risk impact and the second is the uncertainty evaluation (considering [1] approach) based on [12, 13]. These survivability groups are later associated to four categories of corrective actions required: no change of objectives, mild change of objectives, important change of objectives, and fundamental change of objectives.

\section{Results}

The general methodology of energy assessment is created. The specifications for the Lithuania energy assessment model are made:

1) The main Lithuanian energy sources and grids are chosen to the model and the interdependencies among them are defined.

2) The technical, economical, socio-political and terroristic challenges are defined using technical reliability reports, economical modelling. The initiating events were defined. The probabilities of them are selected referencing to other experts studies.

\section{References}

[1] Serbanescu D., Colli A. \& Vetere Arellano A.L. 2008 On some aspects related to the use of interrated risk analyses for the decision making process, including its use in the non-nuclear applications. Safety, reliability and risk analysis: theory, methods and applications: proceedings of the European safety and reliability conference (ESREL 2008), Valencia, Spain, September 22-25, 2008. London: CRC Press Taylor \& Francis Group, 2009.

[2] Augutis, J., Krikštolaitis R., Matuzienè, V., R., Pečiulytė, S. Assessment of Lithuanian power supply security depending on nuclear energy. // 
SAFE 2009: Proceeding of the Third international conference on Safety and Security Engineering, 1-3 July 2009. Rome, Italy.

[3] Augutis, J., Krikštolaitis, R., Matuzienè, V. \& Pečiulytė, S. 2008a. Assessment of energy supply security indicators for Lithuania. Safety, reliability and risk analysis: theory, methods and applications: proceedings of the European safety and reliability conference (ESREL 2008). Valencia, Spain. London: CRC Press Taylor \& Francis Group, 2009. Vol. 1:3101-3107.

[4] Augutis, J., Krikštolaitis, R., Šidlauskas, K., Martišauskas, L. \& Matuzienè, V. Modelling of energy supply disturbances in network systems // ESREL 2009: Proceedings of the European safety and reliability conference 2009, 7-10 September, Prague, Czech Republic.

[5] Serbanescu D. 2004. Some insights on issues related to specifics of the use of probability, risk, uncertainty and logic in PRA studies, Int. J. Critical Infrastructures, Vol. 1, Nos. 2/3, 2004.

[6] Lithuanian Energy 2000-2007 // Lietuvos ūkio ministerija, Lietuvos Energetikos Institutas, 2001-2008.

[7] Augutis, J. \& Ušpuras, E. Risk of technologies: monograph. Kaunas: Lithuanian Energy Institute, Vytautas Magnus University, 2006. ISBN 9986-492-89-0 (in Lithuanian).

[8] Alzbutas, R., Kupčiūnienė K., Adlytè, R. \& Augutis J. The Aircraft Crash on the Ignalina NPP Probability Estimation Considering Data Uncertainty // Energetika. 1, pp. 1-9, 2007. ISSN 0235-7208 (in Lithuanian).

[9] Barselina project report, by Lithuanian energy institute, 1991.

[10] Energy supply option for Lithuania. IAEA report, 2004.

[11] Howard et al. 1984. Howard R.A. and Matheson J.E., (editors), Readings on the Principles and Applications of Decision Analysis, 2 volumes (1984), Menlo Park CA: Strategic Decisions Group, 1984.

[12] Smithson, Michel J. 2000. Human judgment and imprecise probabilities, web site of the imprecise probabilities project http://ippserv.rug.ac.be 1997-2000 by Michel J. Smithson and the Imprecise Probabilities Project, 2000 . 